\title{
DESCARTE DE RESÍDUOS SÓLIDOS E CONFLITOS NO ESPAÇO PÚBLICO NO NÚCLEO CENTRAL DE ITUIUTABA, MINAS GERAIS, BRASIL
}

\author{
SOLID WASTE DISPOSAL AND CONFLICT IN PUBLIC SPACE IN CENTRAL \\ BUSINESS DISTRICT IN ITUIUTABA, MINAS GERAIS, BRAZIL
}

\author{
ELIMINACIÓN DE RESIDUOS SÓLIDOS Y CONFLICTOS EN EL ESPACIO \\ PÚBLICO EN EL NÚCLEO CENTRAL DE ITUIUTABA, MINAS GERAIS, BRASIL \\ Humberto Ferreira Silva Minéu - Universidade Federal de Uberlândia - Uberlândia - Minas Gerais - Brasil \\ hmineu@gmail.com
}
Vitor Ribeiro Filho - Universidade Federal de Uberlândia - Uberlândia - Minas Gerais - Brasil ribeirofilho.vitor@gmail.com
Manfred Fehr - Universidade Federal de Uberlândia - Uberlândia - Minas Gerais - Brasil
josemanf@yahoo.com

\begin{abstract}
Resumo
Esta pesquisa aborda a gestão de resíduos sólidos urbanos do ponto de vista do espaço público ocupado com o seu descarte no Núcleo Central de Ituiutaba, Minas Gerais, Brasil, e os conflitos e efeitos negativos para a sociedade. Os objetivos da pesquisa são identificar e quantificar o uso do espaço público no descarte dos resíduos sólidos, as relações de conflitos com acessibilidade e mobilidade, os efeitos na ambiência e os valores econômicos. No estudo de caso foi realizada a observação, registro fotográfico, identificação das situações de conflitos e medição da área e do volume dos espaços ocupados pelo descarte dos resíduos. Foram quantificados os coletores existentes na área (fixos) e os pontos de descarte de resíduos deixados nas calçadas (móveis). Num espaço de doze quarteirões são identificados os pontos fixos e móveis que os residentes e comerciantes usam para descartar seus resíduos. 0 conjunto dos pontos ocupa 102 metros quadrados, sendo apresentados seus valores imobiliários. A presença dos resíduos interfere na mobilidade de pessoas e veículos, afeta o serviço de limpeza pública e produz impactos visuais negativos. Na ausência de regulamentação municipal, elabora-se uma proposta de mitigação dos conflitos.

Palavras-chave: espaço público, resíduos sólidos, Núcleo Central, gestão de resíduos.
\end{abstract}

\section{Abstract}

The paper addresses the management of urban solid waste from the perspective of public space occupied by waste disposal in the Central Business District of Ituiutaba, Minas Gerais, Brazil, as well as the conflicts, and the negative effects for society. The research aims to identify and quantify the use of public space for the disposal of solid wastes, the conflicting relations regarding accessibility and mobility, the effects on the surroundings and on economic values. Observation, photographic register, identification of conflict situations, along with measurement of area and volume of the spaces occupied by waste disposal were carried out for the case study. Existing fixed collectors and mobile spots for waste disposal on sidewalks used by residents and shopkeepers were identified and quantified within an area of twelve blocks. The set of spots are located within 1,097.92 square feet. The study also shows its real estate prices. The presence of wastes jeopardizes 
the mobility of people and vehicles, affects urban cleaning services, and creates negative visual impacts. In the absence of municipal regulations, the paper presents a proposal to avoid conflicts.

Keywords: public space, solid waste, Central business district, waste management.

\section{Resumen}

Esta investigación se ocupa de la gestión de los residuos sólidos urbanos desde el punto de vista del espacio público ocupado con su eliminación en el Núcleo Central de Ituiutaba, Minas Gerais, y de los conflictos y efectos negativos para la sociedad. La investigación tiene como objetivo identificar y cuantificar el uso del espacio público en la eliminación de los residuos sólidos, las relaciones de conflictos con accesibilidad y movilidad, los efectos en el ambiente y los valores económicos. En el estudio de caso se realizaron la observación, el registro fotográfico, la identificación de las situaciones de conflictos y la medición del área y del volumen de los espacios ocupados por la eliminación de los residuos. Fueron cuantificados los colectores existentes en el área (fijos) y los puntos de eliminación de residuos dejados en las aceras (móviles). En un espacio de doce cuadras son identificados los puntos fijos y móviles que los residentes y comerciantes utilizan para deshacerse de sus residuos. El conjunto de puntos ocupa 102 metros cuadrados y se presentan sus valores inmobiliarios. La presencia de residuos interfiere en la movilidad de las personas y los vehículos, afecta el servicio de limpieza pública y produce impactos visuales negativos. Como no hay reglamentación municipal, se elabora una propuesta para resolver los conflictos.

Palabras-clave: espacio público, residuos sólidos, Núcleo Central, gestión de residuos.

Introdução

A cidade é vista como uma forma de organização do espaço pelo homem, refletindo as características da sociedade e que, na acepção da metrópole moderna, constitui-se num produto da economia de mercado. A organização do espaço na cidade ocorre com usos extremamente diferenciados, como na área central e regiões de uso industrial e residencial, afetados pelos fluxos diários entre local de trabalho e residência, fluxos de consumidores e do próprio capital (Corrêa, 1997).

Santos (1998, p. 25) entende o espaço como o "resultado da ação dos homens sobre o próprio espaço, intermediado pelos objetos, naturais e artificiais". O espaço é visto "como uma realidade relacional, coisas e relações juntas", com objetos físicos e atividades humanas em interação contínua.

De modo complementar, Santos (2008, p. 67) entende que o espaço “[...] constitui uma realidade objetiva, um produto social em permanente processo de transformação. O espaço impõe sua própria realidade; por isso a sociedade não pode operar fora dele”.

Na ocupação do espaço urbano ocorre a concentração de atividades com diversos usos do solo, tais como o comércio, os serviços e o transporte, num processo de centralização, formando a Área Central, sendo essa “[...] um produto da economia de mercado levado ao extremo pelo capitalismo industrial” (Corrêa, 1997, p. 123). 
Essa concentração promove uma valorização econômica significativa do espaço urbano, configurando a busca do aproveitamento maximizado do metro quadrado pelos atores sociais que produzem o espaço urbano, com destaque na Área Central e maior intensidade no Núcleo Central (NC).

$\mathrm{O}$ NC emerge dos estudos da estrutura interna da cidade em relação à formação do espaço urbano, com o modelo da Escola de Chicago tornando-se o mais conhecido. Esse modelo "baseia-se na expansão radial da cidade de Chicago, no começo do século XX, a partir do núcleo central, denominado Distrito Central de Negócios (Central Business District CBD)" (Strohaecker, 1988, p. 171).

O CBD foi caracterizado por Murphy, Vance e Epstein (1955) apud Ribeiro Filho (2004, p. 156) envolvendo como critérios "o valor da terra, a intensidade comercial, a verticalização e o fluxo de pedestres e veículos”, com o valor da terra sendo "o aspecto essencial que permeia a organização interna do núcleo [...]”.

$\mathrm{O}$ alto valor do solo no $\mathrm{NC}$ induz aos empreendimentos explorarem ao máximo a sua área interna e obter o maior retorno sobre o investimento, seja pela compra (propriedade) ou aluguel e impostos. Assim, atividades privadas realizadas no espaço público promovem a ocorrência de externalidades negativas e socialização de custos privados.

O conceito de externalidade foi formulado inicialmente por Pigou, em 1920, sendo em período mais recente trabalhado junto à questão ambiental, em decorrência do agravamento da qualidade ambiental e o custo de despoluição assumir valores significativos (Maimon, 1992).

Para Maimon (1992, p. 26), as “externalidades manifestam-se quando os preços de mercado não incorporam completamente os custos e benefícios dos agentes econômicos [...]". Assim, os custos privados se tornam distintos dos custos sociais, de modo que a aplicação apenas da economia convencional leva a maximização dos custos privados e na socialização dos problemas ambientais e sociais.

De acordo com Field e Field (2014, p. 51), "os custos privados de uma ação são os custos enfrentados pela parte que toma as decisões que levam a essa ação.” Enquanto que os "custos sociais de uma ação são todos os custos da ação, independente de quem os enfrenta". Os autores reforçam que os custos sociais incluem os custos privados, mas podem incluir muito mais em certas situações.

A relação de consumo no NC promove a geração de resíduos sólidos (RS) que demandam a destinação final ambientalmente adequada, 
definida pela lei 12.305, de 12 de agosto de 2010, art. $3^{\circ}$, inciso VII, como a "destinação de resíduos que inclui a reutilização, a reciclagem, a compostagem, a recuperação e o aproveitamento energético ou outras destinações admitidas pelos órgãos competentes [...]” (Brasil, 2010, p. 2).

O descarte inadequado, com a ocupação de espaços públicos, gera situações de sujeira, conflitos com a acessibilidade e mobilidade, efeitos negativos na drenagem urbana e na ambiência e, consequentemente, perda de bem-estar das pessoas e maior dificuldade para os trabalhadores do serviço de limpeza pública.

Na mediação dos conflitos entre os diversos usos e atores na modelagem do espaço e sua ocupação, está o Estado, como ator e árbitro na organização e reorganização do espaço urbano (Corrêa, 1997). Esse papel encontra-se definido na Constituição Federal de 1988, art. 30, com o poder público sendo responsável pela coleta e destinação dos RS.

Com o estabelecimento da Política Nacional de Resíduos Sólidos (PNRS), instituída pela Lei n. 12.305/2010, criou-se um marco regulatório nacional para tratar da gestão dos resíduos sólidos, com princípios, objetivos, conceitos, responsabilidades e proibições.

Um dos objetivos da PNRS é a gestão integrada de resíduos sólidos (GIRS), definida no art. $3^{\circ}$, inciso XI, como "conjunto de ações voltadas para a busca de soluções para os resíduos sólidos, de forma a considerar as dimensões política, econômica, ambiental, cultural e social, com controle social e sob a premissa do desenvolvimento sustentável” (Brasil, 2010, p. 2).

A gestão integrada propõe uma abordagem sistêmica e integrada de caráter multidisciplinar na análise dos problemas e busca das soluções, proporcionando a aplicação de conhecimentos diferentes para tratar da questão dos resíduos sólidos e sua relação com a sociedade e o ambiente, os diversos atores sociais e suas responsabilidades.

No NC predomina a geração de Resíduos Sólidos Urbanos (RSU), cuja classificação quanto à origem pela PNRS, art. 13, inciso I, engloba os resíduos domiciliares (originários das atividades em residências) e os resíduos de limpeza urbana (originários da varrição, limpeza de logradouros e vias públicas) (Brasil, 2010).

Os resíduos gerados pelos empreendimentos comerciais e prestadores de serviços, caracterizados como não perigosos podem ser equiparados pelo poder público aos resíduos domiciliares, conforme sua natureza, composição ou volume (Brasil, 2010). Assim, passam a ser recolhidos pelo serviço de limpeza pública da cidade, compondo os RSU. 
Os dispositivos utilizados para o acondicionamento dos resíduos sólidos (contêineres, lixeiras, coletores) representam pontos de descarte até a coleta pelo serviço de limpeza pública. A distribuição desses dispositivos no espaço urbano representa um dos aspectos relevantes no sistema de coleta, aliado ao comportamento das pessoas e ao local e horário em que os resíduos dos empreendimentos são descartados.

No intuito de obter melhor análise e apreensão em relação ao uso do espaço público com o descarte de resíduos e os conflitos existentes, optou-se por uma abordagem integrada entre a geografia, a gestão integrada de resíduos sólidos e a economia ambiental.

A integração dessas áreas ocorre por meio das dimensões política, econômica, ambiental, cultural e social da Gestão Integrada de Resíduos Sólidos (Brasil, 2010); do processo de análise e construção do espaço diante do exame da totalidade, onde as inter-relações entre os fatores "não raro tornam extremamente difícil separar as influências sobre um espaço definido [...]" (Santos, 2008, p. 71); o papel do Estado como ator e mediador dos conflitos (Corrêa, 1997); de que "[...] o econômico, o social, o político e o cultural estão juntos, compondo um quadro harmônico no âmbito da formação espacial [...]" (Corrêa, 2000, p. 18); e da incorporação das externalidades negativas para a internalização dos custos sociais pelos empreendimentos (Maimon, 1992; Field; Field, 2014).

Essa análise visa compreender melhor a complexidade dos fatores que formam o contexto, essa "totalidade", que na visão de Santos (2008, p. 71), "é uma construção válida no exame da complexidade de fatores a serem examinados na análise do contexto espacial." Para o autor, por a totalidade ser um conceito abrangente e que não se pode estudar o todo pelo todo, cabe dividir o todo em suas partes para um exame mais concreto.

Para Santos (1998, p. 17), "As mudanças que o território vai conhecendo, nas formas de sua organização, acabam por invalidar os conceitos herdados do passado e a obrigar a renovação das categorias de análise". Assim, com a interdependência entre variáveis, com umas sendo causa e ou consequência de outras, o valor real está na análise em conjunto.

Essa abordagem, integrando áreas de conhecimento na pesquisa, também é defendida em Santos (2011, p. 80), entendendo a interdisciplinaridade como "única forma de dar conta dos fenômenos ligados à modernidade", sugerindo "uma mudança de enfoque no tratamento dados aos problemas humanos". Para o autor, mudanças no uso e na gestão do território se impõem se queremos criar um novo tipo de cidadania, em 
confronto ao que ocorreu no Brasil, que em lugar de cidadão, formou-se um consumidor.

Portanto, ao estudar o espaço, cumpre apreender sua relação com a sociedade, as atividades que ocorrem no local e contexto analisado, que levam a diversos usos, que compõem uma determinada totalidade.

Assim, a pesquisa busca identificar e quantificar o espaço público usado no descarte dos resíduos sólidos para a coleta diária no Núcleo Central, as relações de conflitos com a acessibilidade e mobilidade urbana, os efeitos na ambiência e os valores imobiliários envolvidos na ocupação do solo. Também, procurou-se contribuir com sugestões para melhor utilização do espaço, com menos impactos negativos e melhoria de bem-estar.

\section{Procedimentos metodológicos}

A modalidade de pesquisa utilizada foi o método do estudo de caso, que consiste em "uma investigação empírica que investiga um fenômeno contemporâneo dentro de seu contexto da vida real, especialmente quando os limites entre o fenômeno e o contexto não são claramente definidos" (Yin, 2001, p. 32). Uma característica desse método é se basear "em várias fontes de evidências, com os dados precisando convergir [...]” (Yin, 2001, p. 33).

O estudo exploratório foi realizado em um primeiro momento para melhor conhecimento e delimitação do espaço a ser estudado e a diversidade de usos existentes.

A pesquisa bibliográfica foi utilizada para a busca de estudos sobre a temática, delimitação da área para levantamento de dados empíricos, referencial para análise e interpretação e a forma de apresentação dos resultados.

No trabalho de campo, o espaço foi observado e fotografado em dias e horários alternados, no período de maio a julho de 2013. As atividades envolveram a identificação dos usos do espaço público, as situações positivas e negativas encontradas, o horário de descarte pelos estabelecimentos, a forma de descarte (nos contêineres e coletores ou nas calçadas), ocorrências de barreiras à circulação das pessoas, interferência nas áreas de estacionamento, interferência de coleta durante o dia por catadores de material reciclável, efeitos na ambiência e no sistema de drenagem urbana.

Os relatos dos trabalhadores do serviço de limpeza foram obtidos por meio da entrevista focal que, conforme Yin (2001, p. 113), são entrevistas 
"espontâneas e assumem o caráter de uma conversa informal", mas seguindo certo conjunto de perguntas. Nesse formato, o entrevistador permite ao entrevistado falar livremente sobre o assunto, mas sem desviar, de modo a explorar a experiência vivida em condições determinadas (Gil, 2006).

Essas entrevistas, na forma de conversas informais com duas duplas de trabalhadores que atuavam no NC, complementaram os trabalhos de observação sobre os usos, conflitos e efeitos negativos do descarte de resíduos de forma inadequada.

Os locais (pontos) de descarte dos RS foram divididos em pontos fixos e móveis. Os pontos fixos envolvem contêineres, coletores e "lixeiras" instalados (Figura 1). Os pontos móveis são os locais de descarte com os resíduos deixados nas calçadas e ou na rua.

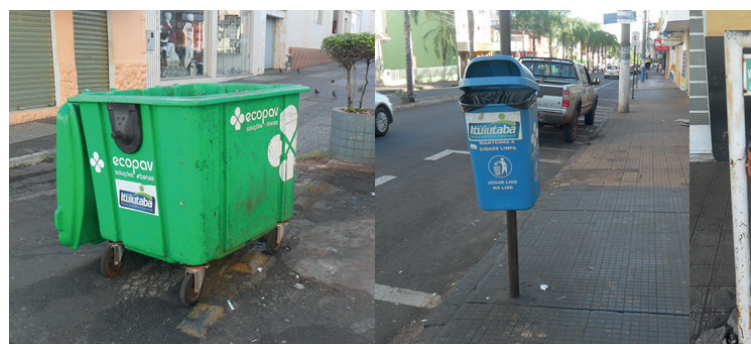

A

B

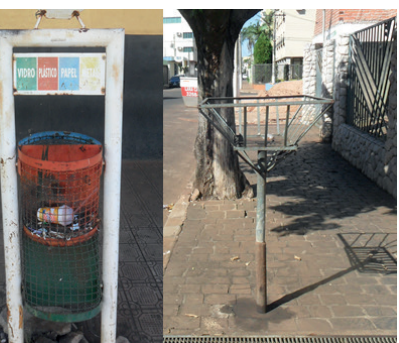

D

Figura 1 - Tipos de coletores (pontos fixos) na área de estudo (A-contêiner, B-coletor de fibra boca de lobo, C-coletor de recicláveis antigos e D-lixeiras utilizadas em residências)

Fonte: MINÉU, H. F. S. (Jun./2013)

Em cada ponto, fixo e móvel, foi realizada a medição de comprimento, largura e altura, para obtenção da área e do volume ocupado pelos resíduos em caráter permanente (pontos fixos) ou temporários (pontos móveis).

Os pontos fixos foram medidos no domingo (30/06), devido ao menor trânsito e circulação de pessoas. Os pontos móveis foram medidos no período de quarta-feira (10/07) a sexta-feira (12/07), segunda-feira (15/07) e terça-feira (16/07), a partir das 17 h45, de modo a obter os dados próximo ao fechamento do comércio e antes da coleta dos resíduos pelo serviço de limpeza pública e coleta seletiva pela Cooperativa de Reciclagem.

Para a valoração dos espaços ocupados pelos pontos descarte, utilizou-se o valor do metro quadrado na área objeto de estudo conforme 
valores em estudos pela Prefeitura para a revisão (atualização) da cobrança do Imposto Predial e Territorial Urbano (IPTU).

A delimitação da área central e do núcleo central foi utilizada conforme trabalho de Teixeira e Oliveira (2011), complementada com levantamento de campo com GPS Garmin 64s, confecção de camada SHP para incorporação no mapa georreferenciado, com uso do software Quantum GIS (QGIS), versão 2.8.3.

O perímetro urbano do município foi obtido junto à Prefeitura, por meio da Secretaria de Planejamento, em mapa digitalizado no formato DXF, importado para o QGIS, georreferenciado e inserido no mapa de localização.

Caracterização do município e da área de estudo

O município de Ituiutaba (Figura 2) localiza-se na região do Triângulo Mineiro, Minas Gerais, Brasil, com uma população estimada em 2014 de 102.690 habitantes. O município apresentou uma evolução significativa no IDH nas últimas décadas, evoluindo de 0,535 em 1991, para 0,653 em 2000 e chegando a 0,739 em 2010 (IBGE, 2015).

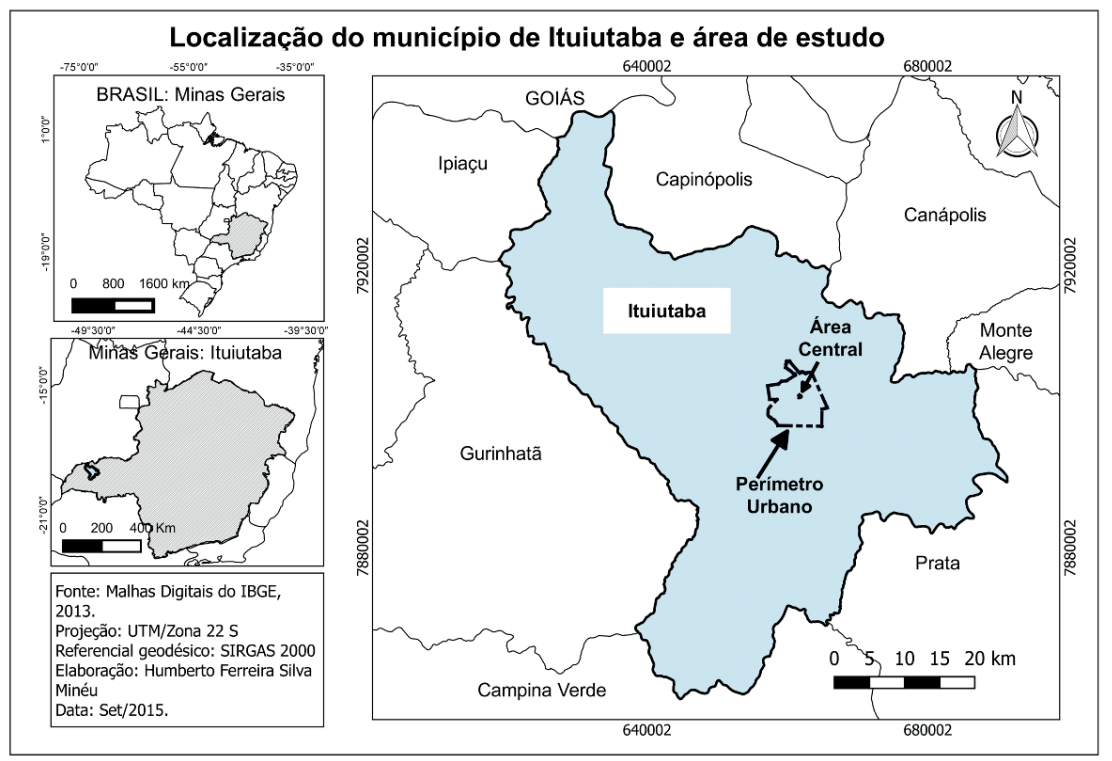

Figura 2 - Localização do município de Ituiutaba, Minas Gerais, Brasil. 
A geração de resíduos sólidos é crescente no município (Tabela 1), influenciada pelo crescimento populacional, melhoria de renda, aumento da atividade econômica e expansão urbana.

Tabela 1 - Evolução dos resíduos sólidos urbanos destinados ao aterro sanitário (T)

\begin{tabular}{|c|c|c|c|c|}
\hline & $\mathbf{2 0 0 8}$ & $\mathbf{2 0 1 0}$ & $\mathbf{2 0 1 2}$ & $\mathbf{2 0 1 4}$ \\
\hline Total anual (T) & $19.726,43$ & $20.784,72$ & $24.368,87$ & $23.584,44$ \\
\hline Média mensal (T) & $1.643,869$ & $1.732,06$ & $2.030,739$ & $1.965,37$ \\
\hline
\end{tabular}

Fonte: Prefeitura Municipal de Ituiutaba/Secretaria de Obras

Organização: MINÉU, H. F. S. (2015)

O município dispõe de aterro sanitário e coleta seletiva por meio de cooperativa, com as coletas convencional e seletiva realizadas diariamente na área de estudo.

A área de estudo foi delimitada como o Núcleo Central (NC) da cidade de Ituiutaba, conforme estudo de Teixeira e Oliveira (2011). Nas vias no limite do NC com a Zona Periférica ao Centro e Zona Mista os espaços ocupados com resíduos foram avaliados nos dois lados, por considerar que a geração e coleta ocorre na rua como um todo.

\section{Os usos do espaço público no Núcleo Central}

Os usos observados pela pesquisa envolvem: os resíduos sólidos nas calçadas (pontos móveis); contêineres e lixeiras (pontos fixos); a circulação intensa de pedestres e veículos; o estacionamento de carros, motos e bicicletas; circulação de ciclistas e de veículos de carga; o fluxo das onze linhas de ônibus que atendem a cidade; o comércio informal; catadores de materiais recicláveis; e, os trabalhadores do serviço de limpeza urbana.

Essa diversidade de usos, com intensidade, aflora problemas inevitáveis em função de o espaço ser limitado. O espaço não expande e retrai conforme a demanda e dinâmica das atividades, sendo o espaço físico um só para atender a todas as atividades.

Essa situação requer a participação do Estado, tendo como premissa o marco regulatório estabelecido pela PNRS (Brasil, 2010), representado pelo poder público local, de forma a influenciar a ação dos atores e amenizar os conflitos diante dos diversos usos, conforme aponta Corrêa (1997), e que os custos sociais sejam internalizados pelos empreendimentos (Maimon, 1992). 
Assim, tem-se uma totalidade complexa, conforme Santos (2008). A economia, a política, as relações sociais, a paisagem, a cultura e as questões ambientais mudam, sendo que medidas adotadas em uma dessas dimensões afetam outra(s). Cabe, então, a análise de cada dimensão dessa totalidade (política/legal, econômica, cultural, social, tecnológica, ecológica) para melhor compreender o contexto e as relações de causa e efeito e trabalhar no processo de (re)construção do espaço estudado e das relações existentes.

\section{Organização espacial dos resíduos sólidos no Núcleo Central}

A distribuição espacial dos pontos de descarte de RS para a coleta no Núcleo Central foi representada em pontos fixos (89) e móveis (116), totalizando 205 pontos (Figura 3).

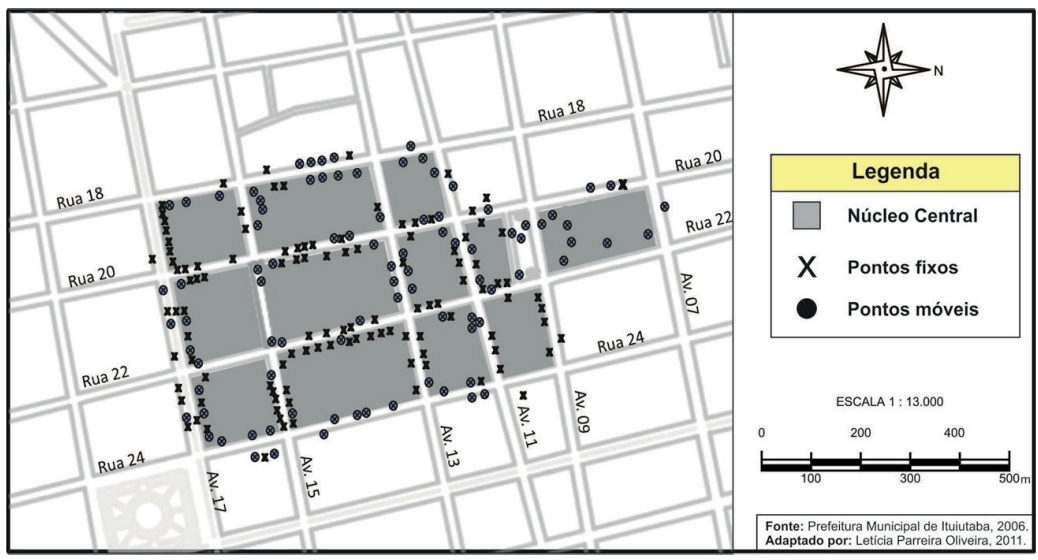

Figura 3 - Distribuição de RS em pontos fixos e móveis no Núcleo Central Fonte: Elaboração da distribuição dos pontos por Minéu (2014), organização da figura por Letícia Parreira Oliveira (2014).

Os pontos fixos apresentam distribuição ao longo do NC, sendo esperado por se tratar de distribuição planejada de contêineres e coletores pelo serviço de limpeza pública e coletores/lixeiras instalados em residências (nas calçadas) pelos proprietários. Nesses pontos, foram incluídos tambores de 200 litros usados nas calçadas por alguns estabelecimentos comerciais e edifícios residenciais para o descarte de seus RS, por representarem ocupação permanente do espaço público. 
Em relação aos pontos móveis, verificou-se a concentração dos mesmos nas ruas 20 e 22, entre as Av. 17 e 11; na Av. 17, entre as ruas 18 e 24; e, na Av. 15, entre as ruas 22 e 24. Este espaço coincide com o de maior atividade comercial e serviços e o fluxo de pedestres, confirmado pelo relato dos trabalhadores da limpeza pública, com os resíduos em meio a motos e carros e as pessoas descartando resíduos logo após um local ser limpo.

O padrão espacial representa um ponto de partida para "questionamentos sobre a gênese, a dinâmica, os agentes sociais e suas práticas, assim como a respeito dos impactos das formas sociais sobre a sociedade" (Corrêa, 2000, p. 9). Nesse sentido, fluxos e fixos desempenham papel relevante ao influenciar os arranjos e os deslocamentos.

A organização espacial dos pontos móveis, acompanhando a distribuição espacial mais intensa da atividade comercial, dos serviços e dos fluxos, corrobora a afirmação de Corrêa (2000) e reforça a necessidade da busca de melhoria das condições para a própria sociedade. Essa melhoria envolve a aplicação da PNRS, por meio da gestão integrada de resíduos sólidos (Brasil, 2010) e promove a (re)construção do espaço com uma nova relação com a sociedade (Santos, 2008), integrando a atividade do comércio, o uso do espaço e o bem-estar das pessoas, contribuindo para minimizar os conflitos.

\section{Conflitos e efeitos do descarte de resíduos sólidos no núcleo central}

Os conflitos decorrentes do descarte de resíduos pelos residentes, empreendimentos e usuários, identificados na pesquisa envolveram: barreiras à circulação das pessoas; interferência no acesso de motoristas e motociclistas ao estacionamento e aos veículos; catadores (em várias formas de tração) para recolher o material reciclável afetando o trânsito; o transporte coletivo em parar adequadamente no ponto com interferência de catador; e, maior esforço e riscos aos trabalhadores do serviço de limpeza pública.

Esses conflitos revelam a disputa pelo espaço entre as diversas atividades, com os atores procurando exercer o seu interesse - vender, comprar, locomover, coletar resíduos, o que é relevante para a economia local.

O conflito entre o estacionamento e o acesso aos veículos (carro e moto) com o descarte inadequado dos resíduos (Figura 4), ocorre principalmente com os resíduos sendo dispostos com muita antecedência ao horário da coleta. Outra forma desse conflito é com os coletores fixos, nas ocasiões em que coincidem com as portas dos veículos. 


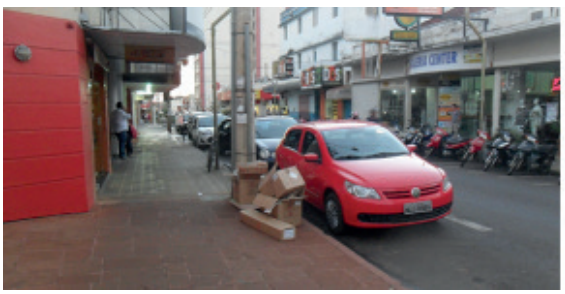

A

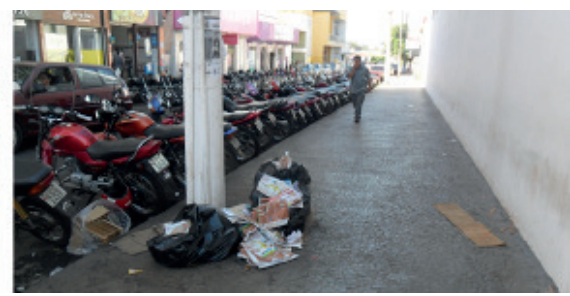

B

Figura 4 - Situação de conflito entre o descarte de RS na calçada com o estacionamento de carros $(A)$ e motos $(B)$

Fonte: MINÉU, H. F. S. (jun./2013)

Um efeito negativo no trânsito é a presença de catadores autônomos com carrinho de mão, veículo utilitário, carroça de tração animal (Figura 5) e carretinha puxada por moto, recolhendo o material reciclável nas calçadas ou nos contêineres ao longo do dia.

Esse conflito fica mais intenso no final da tarde, quando as lojas no final do expediente colocam mais material na calçada, atraindo maior número de catadores, o que coincide com o horário de maior movimento no trânsito.

Os RS nas calçadas durante o dia promovem redução do espaço para as pessoas caminharem, afetando a acessibilidade e mobilidade (Figura 6A), ou criando barreira à circulação das pessoas, principalmente com cadeira de rodas, carrinho de criança ou andador (Figura 6B).

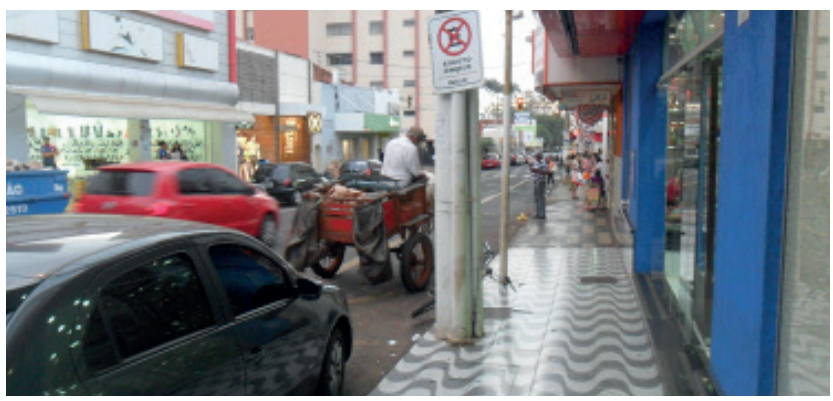

Figura 5 - Catador autônomo na coleta de material reciclável com tração animal em disputa de espaço com fluxo de veículos, estacionamento e ponto do transporte coletivo 


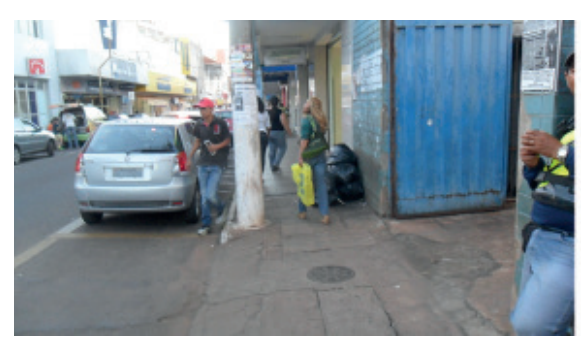

A

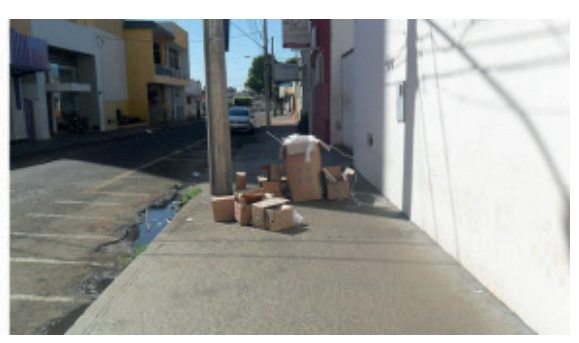

B

Figura 6 - Demonstração do efeito negativo do descarte inadequado de resíduos nas calçadas afetando (A) ou impedindo (B) a circulação das pessoas

Fonte: MINÉU, H. F. S. (jul./2013)

No período de realização da pesquisa não foi observada a presença do poder público quanto à orientação ou fiscalização que atenuassem os conflitos. Também não foram identificadas medidas ou regulamentações para os atores que atuam no NC, divergindo do entendimento de Corrêa (2000), em que o Estado atua como ator e mediador dos conflitos.

Observou-se, também, situação "criativa” no descarte dos RS durante o dia (Figura 7A), com os RS sob o material de mídia do empreendimento, o que não significa que esteja correta, especialmente ao confrontarmos com a PNRS (Brasil, 2010). São alternativas que cada gerador busca, individualmente, em função da carência de um trabalho de articulação da solução em caráter coletivo, pelo poder público e ou entidades associativas.

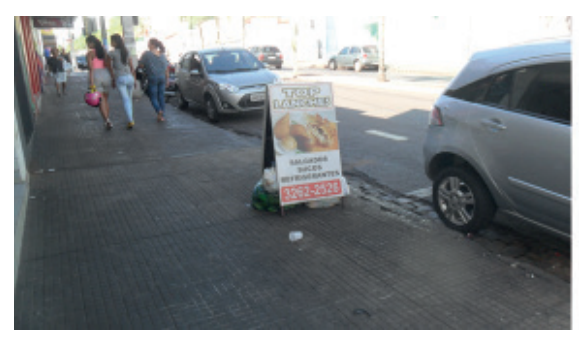

A

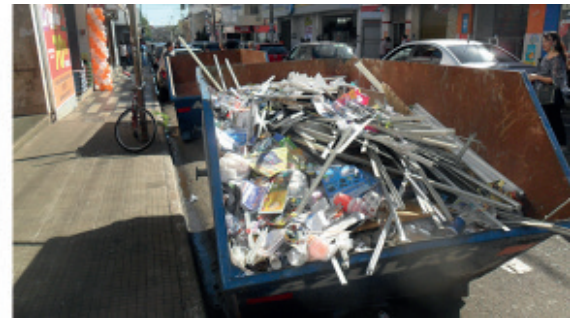

B

Figura 7 - Alternativas usadas pelo comércio e pelas pessoas para destinar os resíduos embaixo de placa de comunicação do negócio (A) e caçambas (B) 
A Figura 7B ilustra o descarte inadequado em caçambas, com as pessoas utilizando-as para "se livrar" do seu resíduo no primeiro lugar em que encontra, embora destinadas a recolher entulho. Isso aumenta o problema, pois com a mistura perde-se qualidade do resíduo de construção e a perda de RS a serem encaminhados para a coleta seletiva.

Um comportamento comum das pessoas é o descarte inadequado dos RS nas ruas, em função do simples hábito de jogá-los no chão na medida em que circulam. A dispersão desses resíduos afeta a ambiência do local (Figura 8A), induzindo novas ações de descarte inadequado e sujando locais pouco depois de realizada a limpeza.

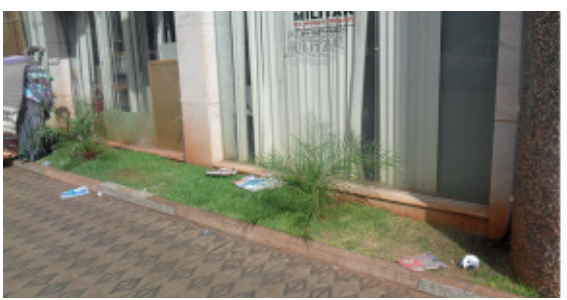

A

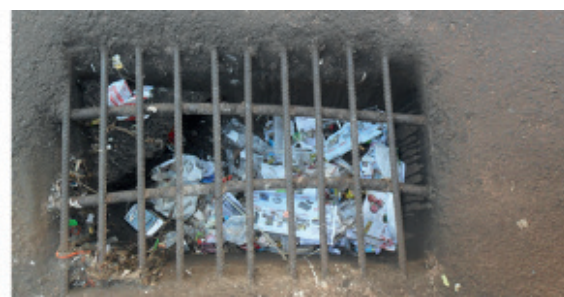

B

Figura 8 - Efeito do descarte inadequado de RS na ambiência (A) e na drenagem (B)

Fonte: MINÉU, H. F. S. (jul./2013)

Os resíduos descartados pelas pessoas também afetam de forma significativa o sistema de drenagem urbana (Figura 8B), com redução de sua capacidade e até situações de entupimento. Os RS que mais causam esses problemas são os materiais de publicidade (encartes, folhetos), distribuídos aos consumidores pelas lojas e agentes da mídia ou quando fixam em carros e motos estacionados. Esses materiais são, em grande parte, descartados pelas pessoas durante a circulação no NC ou na rua ao chegar ao seu veículo.

O fato de os resíduos caírem na sarjeta, junto ao meio fio, causa maior dificuldade para os trabalhadores do serviço de limpeza pública, que relataram que o material vai se espalhando nos estacionamentos, tornando o serviço mais lento, trabalhoso e afetando a qualidade.

Essas situações ilustram a relação da sociedade com o espaço em um determinado contexto, corroborando com Santos (2008), em que a ação das pessoas e empreendimentos em coletividade influencia a ocupação do espaço. 
A questão econômica na ocupação do espaço público com resíduos sólidos no Núcleo Central

No levantamento foram encontrados 89 pontos fixos (contêineres, coletores e lixeiras), ocupando uma área de 44,3 $\mathrm{m}^{2}$ e um volume de 55,1 $\mathrm{m}^{3}$. Em relação aos pontos móveis, foram encontrados, em média, 116 pontos, ocupando uma área $58,1 \mathrm{~m}^{2}$ e volume de $28,9 \mathrm{~m}^{3}$ (Tabela 2).

Tabela 2 - Quantidade, área e volume ocupado com pontos móveis para o descarte de resíduos sólidos no Núcleo Central

\begin{tabular}{|c|c|c|c|}
\hline Dia da semana & $\mathbf{N}^{\mathbf{0}}$ de pontos & Área $\left(\mathbf{m}^{\mathbf{2}}\right)$ & Volume $\left(\mathbf{m}^{\mathbf{3}}\right)$ \\
\hline Quarta-feira (10.07) & 114 & 60,9 & 31,8 \\
\hline Quinta-feira (11.07) & 129 & 76,8 & 43,4 \\
\hline Sexta-feira (12.07) & 112 & 59,5 & 31,7 \\
\hline Segunda-feira (15.07) & 118 & 48,7 & 21,9 \\
\hline Terça-feira (16.07) & 107 & 44,6 & 15,8 \\
\hline Média & $\mathbf{1 1 6}$ & $\mathbf{5 8 , 1}$ & $\mathbf{2 8 , 9}$ \\
\hline
\end{tabular}

Fonte: Pesquisa de campo

Organização: MINÉU, H. F. S. (2013).

A maior quantidade de pontos móveis (56,6\%) do que fixos $(43,4 \%)$, bem como em área, sinaliza que o espaço destinado de forma organizada em pontos fixos é insuficiente para receber os RS gerados; que a questão cultural ainda é relevante em manter o descarte dos RS na "porta” (calçada) ou em ponto mais próximo possível; e, a questão econômica em função do alto valor do metro quadrado induz os empreendimentos a não destinarem área própria de armazenamento suficiente até o momento de descarte dos seus resíduos.

A concentração dos pontos móveis no núcleo central, demonstrada na figura 3, coincide com a área de maior valor econômico do metro quadrado. A prefeitura, em trabalho de revisão dos valores para a cobrança do IPTU, avalia o metro quadrado nesta área em $\mathrm{R} \$ 1.805,00$ e no restante da área do $\mathrm{NC}$ o valor ficou em $\mathrm{R} \$ 972,00 / \mathrm{m}^{2}$. Isso influencia as decisões dos gestores em aproveitar ao máximo o retorno do investimento na área (terreno).

Esses valores expressam o quanto a propriedade, o aluguel e o imposto incidente representam de investimento do setor privado, que procura 
explorar ao máximo sua área interna com o negócio. Com isso, reduz o armazenamento de produtos (estoque) e mais ainda, itens como materiais de limpeza, manutenção e os resíduos sólidos. Essa lógica mantém a questão da distinção dos custos privados e custos sociais, com a geração das externalidades e socialização de custos privados, corroborando com Field e Field (2014) e Maimon (1992).

Esse raciocínio e decisão levam ao descarte dos materiais mais volumosos durante o dia (principalmente papelão) em calçadas, muitas vezes ocorrendo o recolhimento por catadores, mas contribui para os conflitos na disputa pelo espaço, afetando a acessibilidade e mobilidade. No final do dia esse processo é intensificado, com o restante dos resíduos sendo descartados no espaço público, representando uma externalidade negativa.

A destinação de espaço interno no estabelecimento para o armazenamento temporário dos resíduos até o momento da coleta ou o descarte dos mesmos em local previamente definido pelo poder público, representa uma forma de internalização dos custos sociais, aproximando o custo privado do custo social. Assim, o preço pago pelo consumidor refletiria melhor o preço socialmente "ótimo", com a incorporação das questões ambientais, no caso em estudo, o descarte correto dos resíduos sólidos.

\section{Considerações finais}

A contribuição do presente trabalho está na sua forma de análise utilizada, feita por meio da abordagem integrada entre a geografia, a gestão integrada de resíduos sólidos e a economia ambiental, numa perspectiva interdisciplinar na pesquisa, como a melhor forma para análise de fenômenos modernos. O estudo abordou o uso do espaço no Núcleo Central com o descarte de resíduos sólidos, com os conflitos gerados e efeitos negativos na ambiência e drenagem urbana.

Os resultados encontrados demonstram uso significativo do espaço público no descarte dos RS, com carência de organização. $\mathrm{O}$ alto valor do metro quadrado induz as atividades produtivas evitarem dispor de área própria para armazenar seus resíduos.

A forma individualizada de cada ator resolver o problema de descarte de seus resíduos no espaço público promove conflitos com a acessibilidade e mobilidade urbana, criando barreiras, restringindo a circulação e afetando a autonomia do ir e vir das pessoas. 
A dispersão dos resíduos afeta a ambiência, o sistema de drenagem urbana e aumenta o esforço dos trabalhadores do serviço de limpeza pública, causando externalidade negativa dos empreendimentos. A destinação final ambientalmente adequada representa um processo de incorporação das externalidades, com a internalização dos custos sociais e o cumprimento da responsabilidade da organização em relação aos seus resíduos sólidos.

A carência de atuação do poder público em orientação, fiscalização, informação e regulamentação quanto ao descarte correto de resíduos sólidos no NC deixa uma lacuna no seu papel de mediador desses conflitos, comprometendo o bem-estar dos atores e consumidores envolvidos.

A questão dos RS nesse espaço envolve a busca de soluções de forma compartilhada entre poder público e setor privado. Assim, para mitigar os problemas encontrados por meio da aplicação das dimensões da Gestão Integrada de Resíduos Sólidos, da geografia e da economia ambiental, sugerem-se como medidas: a) implantação pelos empreendimentos de espaços internos suficientes para o armazenamento temporário dos seus RS, com separação entre recicláveis e não recicláveis; b) incentivo pelo poder público aos empreendimentos e residências que adotarem o espaço interno e a coleta seletiva, por meio, por exemplo, de descontos no IPTU; c) criação do IPTU Verde pelo poder público, oferecendo descontos para os proprietários que adotarem medidas ambientais corretas; d) entrega dos materiais pelos empreendimentos e demais geradores de resíduos sólidos nos locais e horários preestabelecidos pelo poder público na regulamentação local; e) entrega dos materiais recicláveis à Cooperativa de Reciclagem, incentivando a atividade formal e reduzindo a frequência de catadores não formais em horários de fluxo intenso, contribuindo para melhor ordenamento de fluxos no núcleo central; f) ajuste no horário do serviço de varrição, evitando riscos aos trabalhadores e melhores condições de trabalho em horários de menor temperatura e fluxos menos intensos; g) ampliação da capacidade de armazenamento e melhor distribuição espacial dos contêineres para comportar o volume de resíduos gerados e realização da coleta após o encerramento do horário comercial; e, h) orientação e fiscalização pelo poder público junto a consumidores e aos empreendimentos. 


\section{Referências}

BRASIL. Lei $n^{o}$. 12.305, de 2 de agosto de 2010. Institui a Política Nacional de Resíduos Sólidos. Disponível em: <http://www.planalto.gov.br/ccivil_03/_ ato2007-2010/2010/lei/l12305.htm>. Acesso em: 12 jul. 2013.

CORREAA, R. L. Processos espaciais e a cidade. In: Trajetórias geográficas. Rio de Janeiro: Bertrand Brasil, 1997. p. 121-143.

. Comércio e espaço: uma retrospectiva e algumas questões. Textos LAGET - Série Pesquisa e Ensino, n. 2, 2000. p. 23-33.

FIELD, B. C.; FIELD, M. K. Introdução a economia do meio ambiente. 6. ed. Porto Alegre: AMGH, 2014.

GIL, A. C. Métodos e técnicas de pesquisa social. 5. ed. 7. reimpr. São Paulo: Atlas, 2006.

IBGE. Instituto Brasileiro de Geografia e Estatística. Minas Gerais - Ituitaba. Disponível em: <http://www.cidades.ibge.gov.br/xtras/perfil.php?lang=\&codm un $=313420 \&$ search $=$ minas-gerais|ituiutaba $>$. Acesso em: 16 jul. 2015.

MAIMON, D. Ensaios sobre a economia do meio ambiente. Rio de Janeiro: APED, 1992.

RIBEIRO FILHO, V. A área central e sua dinâmica: uma discussão. Sociedade e Natureza, Uberlândia, v. 16, n. 31, p. 155-167, dez. 2004.

SANTOS, M. Metamorfose do espaço habitado: fundamentos teóricos e metodológicos da geografia. São Paulo: Hucitec, 1998.

- Estrutura, processo, função e forma como categorias do método geográfico. In: Espaço e Método. 5. ed. São Paulo: EDUSP, 2008. p. 67-79.

. O espaço da cidadania e outras reflexões. In: SILVA, E. da; NEVES, R.N.; MARTINS, L.B. (Org.). Porto Alegre: Fundação Ulisses Guimarães, 2011. (Coleção O Pensamento Político Brasileiro).

STROHAECKER, T. M. A zona periférica ao Centro: uma revisão bibliográfica. Revista Brasileira de Geografia. Rio de Janeiro, v. 50, n. 4, p. 171-183, out./dez. 1988.

TEIXEIRA, S. C.; OLIVEIRA, H. C. M. de. A conformação do núcleo central de Ituiutaba-MG. Relatório de Iniciação Científica PIBIC/CNPq. UFU. Ituiutaba, 2011.

YIN, R. K. Estudo de caso: planejamento e métodos. 2. ed. Porto Alegre: Bookman, 2001.

Humberto Ferreira Silva Minéu - Possui Graduação em Ciências Agrícolas e Agronomia pela Universidade Federal Rural do Rio de Janeiro. Mestrado em Administração pela Universidade Federal de Lavras. Atualmente é Doutorando em Geografia pela Universidade Federal Fluminense e Professor do Instituto Federal de Educação Ciência e Tecnologia do Triângulo Mineiro/ Campus Ituiutaba. 
Vitor Ribeiro Filho - Graduado pela Universidade Federal de Uberlândia. Mestrado e Doutorado pela Universidade Federal do Rio de Janeiro. Pós-Doutorado pela Universidade de Lisboa - Portugal. Atualmente é professor do Instituto e Programa de Pós-Graduação de Geografia da Universidade Federal de Uberlândia.

Manfred Fehr - Graduação em Engenharia Química pela Université Laval (Canadá). Mestrado pela University of Alberta (Canadá). Doutorado da Université Laval (Canadá) e pós-doutorado pela Kungliga Tekniska Högskolan (Suécia). Atualmente é Professor emérito e colaborador do Instituto de Geografia da Universidade Federal Fluminense.

Contribuição de cada autor no desenvolvimento do artigo:

Todos os autores ofereceram substanciais contribuições científicas e intelectuais ao estudo. As tarefas de concepção e design do estudo, preparação e redação do manuscrito, bem como, revisão crítica foram desenvolvidas em grupo. O primeiro autor ficou especialmente responsável pelo desenvolvimento teórico-conceitual, pela aquisição de dados e suas interpretação e análise; o segundo e terceiro autores, contribuíram pela revisão teórico-conceitual e na discussão dos resultados obtidos.

Recebido para publicação em 14 de agosto de 2016 Aceito para publicação 25 de setembro de 2016 